\title{
Circulation of Campylobacter spp. in rhesus monkeys (Macaca mulatta) held in captivity: a longitudinal study
}

\author{
Márcia Cristina Ribeiro Andrade/ ${ }^{+}$, Sanny Cerqueira de Oliveira Gabeira*, \\ Danielle Abreu-Lopes, Wagner Thadeu Cardoso Esteves**, \\ Mônica de Castro Britto Vilardo**, Jacqueline D'arc da Silva Thomé**, \\ Pedro Hernan Cabello***, Ana Luzia Lauria-Filgueiras**
}

\author{
Centro de Criação de Animais de Laboratório, Departamento de Primatologia-Fiocruz, Av. Brasil 4365, 21040-900 Rio de Janeiro, \\ RJ, Brasil *Núcleo de Experimentação Animal **Setor de Campylobacter, Laboratório de Zoonoses Bacterianas, \\ Departamento de Bacteriologia ***Laboratório de Genética Humana, Departamento de Genética, Instituto Oswaldo Cruz-Fiocruz, \\ Rio de Janeiro, RJ, Brasil
}

Campylobacteriosis is an extremely important zoonosis, circulating freely in the environment. In nonhuman primates kept in open facilities and bred for experimental purposes, the presence of Campylobacter spp. could cause severe damage to the production and interfere with the results of scientific research. In this paper, we assessed the circulation of Campylobacter spp. in a colony of clinically healthy rhesus monkeys (Macaca mulatta) destined to research. The analysis was carried out during seven non-consecutive years. Data showed that despite several changes made in animal management along the studied years in order to control this zoonosis, reduction of bacterial charge did not occur. Significant differences among the age groups and sex were observed. Infants showed higher susceptibility than adult animals. In general males were more infected than females. Modifications adopted in the handling techniques need to be reviewed with the intent of improving the production, reducing bacterial infection of the stock and avoiding undesirable cross reactions in the research carried out with these animals. Therefore, this paper alerts professionals that work directly with captive rhesus monkeys about the risks of Campylobacter spp. infection and possible interference on the experimental procedures.

Key words: nonhuman primates - campylobacteriosis - animal management

Campylobacteriosis is a zoonosis discovered in the XIX century, however it was only recognized and studied in detail since the 1970s. The disease is of worldwide distribution and able to cause since light self-limiting diarrheas to severe enterocolites, abortions, other than gastric infections, and even septicemia leading to death, mainly in children up to five years of age (Acha \& Szyfres 1989). The primary virulence mechanism used by Campylobacter spp. to produce colitis is still unknown. There is however recognized participation of enterotoxins, cytotoxins, and bacterial invasion (Wassenaar 1997). During the last decade, this disease was responsible for severe enteritis in animals and humans (Stutman 1994, Moore et al. 2005).

The disease in animals is relevant from the point of view of public health, seen that animals represent important reservoirs. As refers to the species used for production, Campylobacter interferes with the production results by causing diarrheas that can lead to death (Acha \& Szyfres 1989).

${ }^{+}$Corresponding author: andrade@fiocruz.br

Received 20 June 2006

Accepted 1 November 2006
In the developing countries this agent is of considerable importance among the bacterial diarrheas, being transmitted by contaminated water and food. Lack of hygiene is the principal source of contamination (LauriaFilgueiras \& Hofer 1998, Evans et al. 2003). Poultry and swine play an important role since Campylobacter makes part of the normal intestinal flora of these animals. In general, all animals can be assymptomatic reservoirs and thus represent a serious risk for the human population (Acha \& Szyfres 1989).

Recurring enterocolites caused by Campylobacter spp. are the main cause of morbidity in colonies of rhesus monkeys (Macaca mulatta) held in captivity (Sestak et al. 2003). As laboratory animals and considered reservoirs without clinical manifestations, rhesus monkeys are a potential source of contamination mainly for the healthy animals of the colony and for the professionals working in direct contact with them (Fox 1982). Besides, primates can host bacteria that can result in cross-reactions, jeopardizing the interpretation of experimental results. The infected animals may present with delayed development and weight gain so that the animal cannot be delivered for research. Weanlings with less than six months of age, for example, are much more susceptible to the disease, which generally leads to death (Walker et al. 1986, Russel et al. 1987, Paul-Murphy 1993).

Non-specific enteritis are common findings in laboratory animals and generally the etiologic agent is not 
identified (Russel et al. 1993). The present study evaluates the circulation of Campylobacter spp. in a colony of clinically healthy rhesus monkeys, held in captivity.

\section{MATERIALS AND METHODS}

Animals - All rhesus monkeys of the Primatology Department of the Laboratory Animal Breeding Center (Cecal), Oswaldo Cruz Foundation (Fiocruz), Rio de Janeiro, Brazil were evaluated in the course of seven not consecutive years: from 1995 to 1999, in 2002 and 2003. Along these years we examined a total of 243 samples in 1995; 255 in 1996; 253 in 1997; 272 in 1998; 293 in 1999; 323 in 2002; and 320 in 2003, representing a total of 1959 samples. A single sample per year was collected during the annually medical management. Presently, the Department keeps approximately 450 rhesus monkeys destined to biomedical research.

For analyzing the results, the animals were separated according to sex and age. The ages were divided into infant ( 0 to 12 months), juvenile (13 to 48 months), subadult (49 to 72 months), and adult (older than 73 months). Table I shows the number of animals according to the age group and sex analyzed in each year.

Colony of cynomolgus macaques and squirrel monkeys were also handled. However, data of these studies will be published elsewhere.

Clinical examination - Once a year, during the period April to June, the animals are submitted to a detailed clinical examination. There are no parturitions during this period and thus it is considered ideal for the procedure.

After sedation with ketamine chlorhydrate (10-15 mg/ $\mathrm{kg}$ ), the animals are identified with individual register numbers tattooed at the chest region. A detailed clinical analysis is undertaken, including control of the body temperature, heart and breath rate, and evaluation of the general health status. The animals are submitted to biometric evaluation, consisting in weighing and measuring. Tuberculin test and prophylactic vermifugation are performed. Blood samples are collected for a sera bank for epidemiological studies. Feces are collected for parasitological (fresh feces) and bac- teriological (rectal swab) examinations. Adopted animal management followed the technical protocol preconized by Andrade et al. (2004).

All the studies were conducted according to guidelines set forth in the Guide for the Care and Use of Laboratory Animals and authorized by the Ethics Commission on Animal Experimentation from Fiocruz (number P0042-00).

Processing of samples - For the bacteriological examinations we used swabs and transport medium Cary Blair ${ }^{\mathrm{TM}}$ for conservation of the samples until processing. Collected samples were maintained at $10^{\circ} \mathrm{C}$ of refrigeration, from $2 \mathrm{~h}$ to four days until laboratorial processing. Feces were sent to the Bacterial Zoonosis Laboratory of the Department of Bacteriology, Fiocruz, Rio de Janeiro, Brazil, where they were tested according to a previously commended protocol (Lauria-Filgueiras \& Hofer 1998).

Bacteriological analysis - The samples were seeded on selective medium on the basis of Columbia agar $\left(\right.$ DIFCO $\left.^{\mathrm{TM}}\right)$, supplemented with $5 \%$ blood or $4 \mathrm{~g} \%$ activated carbon, $5 \%$ FPB solution, and $0.5 \%$ antibiotic solution prepared on our own laboratory, with the formula as following: cephalothin $81 \mathrm{mg}\left(\mathrm{Sigma}^{\mathrm{TM}}\right)+$ trimetroprim lactate $25 \mathrm{mg}\left(\right.$ Roche $\left.^{\mathrm{TM}}\right)+$ vancomycin $50 \mathrm{mg}$ $($ Sigma $)+$ acti-dione $10 \mathrm{mg}\left(\mathrm{Upjohn}^{\mathrm{TM}}\right)+$ colistin 11 $\mathrm{mg}\left(\right.$ Sigma $\left.^{\mathrm{TM}}\right)+$ purify water Milli-Q $25 \mathrm{ml}$. The abovementioned medium, which is supplemented and selective is effective for isolation of Campylobacter from symptomatic individuals as well as animals reservoir (non-diarrhoeal).

After $48 \mathrm{~h}$ of incubation, plates that did not present typical growth of Campylobacter were discarded, since other bacteria grow in abundance, disturbing isolation or even visualization of characteristic colonies of Campylobacter, which are extended, growing toward to a striae form with translucent water-like aspect.

After seeding, all material (1959 samples) was incubated at $42^{\circ} \mathrm{C}$ for $48 \mathrm{~h}$ in a microaerophilic atmosphere generated by copper passivation or using commercially available envelopes. Copper passivation is adequate for primary isolation of Campylobacter species and it is a very economical technique previously

TABLE I

Number of studied rhesus monkeys at the Fiocruz Primate Center according to the age group and sex

\begin{tabular}{|c|c|c|c|c|}
\hline \multirow[b]{2}{*}{ Year } & \multicolumn{4}{|c|}{ Age group } \\
\hline & Infant (m/f) & Juvenile (m/f) & Subadult (m/f) & $\operatorname{Adult}(\mathrm{m} / \mathrm{f})$ \\
\hline 1995 & $26(17 / 9)$ & $63(12 / 51)$ & $33(9 / 24)$ & $121(59 / 62)$ \\
\hline 1996 & $16(11 / 5)$ & $66(24 / 42)$ & $55(29 / 26)$ & $118(43 / 75)$ \\
\hline 1997 & $24(16 / 8)$ & $48(19 / 29)$ & $69(37 / 32)$ & $112(31 / 81)$ \\
\hline 1998 & $22(12 / 10)$ & $56(21 / 35)$ & $50(18 / 32)$ & $144(55 / 89)$ \\
\hline 1999 & $52(10 / 42)$ & $46(15 / 31)$ & $38(10 / 28)$ & $157(51 / 106)$ \\
\hline 2002 & $72(37 / 35)$ & $73(14 / 59)$ & $33(20 / 13)$ & $145(47 / 98)$ \\
\hline 2003 & $67(41 / 26)$ & $81(23 / 58)$ & $54(25 / 29)$ & $118(41 / 77)$ \\
\hline
\end{tabular}

$\mathrm{m} / \mathrm{f}$ : number of males/number of females; infant (0 to 12 months), juvenile (13 to 48 months), subadult (49 to 72 months), adult (over 73 months). 
described in national and international literatures (Magalhães et al. 1982, Pennie et al. 1984, Lauria-Filgueiras \& Hofer 1989, Pinheiro et al. 1991), which has been adopted about 20 years in the laboratorial routine of the Bacterial Zoonosis Laboratory of the Department of Bacteriology, Fiocruz.

After incubation, the material was submitted to presumptive diagnosis. Colonies with translucent waterlike aspect were considered suspect. These colonies were stained using the Gram method for identification under optical microscopy. Under the microscope, Campylobacter appears as curved Gram-negative rods in form of sea gulls, or "s" shape.

Biochemical tests for biotyping of species such as sodium hypurate hydrolysis test, indoxyl acetate hydrolysis test, and Dnase enzyme production test were performed for definite diagnosis (Lauria-Filgueiras 2000).

Sensitivity test was carried out using nalidixic acid $30 \mu \mathrm{g}\left(\mathrm{Oxoid}^{\mathrm{TM}}\right)$ and cephalothin $30 \mu \mathrm{g}\left(\mathrm{Oxoid}^{\mathrm{TM}}\right)$ to separate the especies $C$. jejuni and C. coli from the especies C. lari (NCCLS 2004).

Statistical analysis - Differences between age groups and sexes were tested using Chi-Square test.

\section{RESULTS}

According to the performed tests, the species more frequently circulating among the 1959 analyzed animals in the course of the seven studied years were $C$. coli (10.06\% of isolated samples) and C. jejuni (6.53\%). Other species were not typed and classified as Campylobacter spp. (24.6\%) (Table II).

Figs 1 to 4 demonstrate the frequencies of $\mathrm{Cam}$ pylobacter according to the age group during the respective years. Chi-Square test showed highly significant differences in all age categories overall the years $(\mathrm{P}<0.01)$.

Table III shows the difference of frequency between sexes, expecting the years 1995 and 1997 . We must point out the higher positivity in males than females, except for the year 2003 .

Antibiotic sensitivity test revealed sensitivity to nalidixic acid and resistence to cephalothin when the especies $C$. jejuni and $C$. coli were involved, while $C$. lari showed resistant to both antibiotic drugs.

\section{TABLE II}

Prevalence (\%) of C. coli, C. jejuni, and Campylobacter spp. isolated during the seven studied years at the Fiocruz Primate Center

\begin{tabular}{ccccc}
\hline Year & $\mathrm{n}$ & C. coli & C. jejuni & Campylobacter spp. \\
\hline 1995 & 243 & 2.88 & 0.82 & 30.45 \\
1996 & 255 & 15.68 & 4.76 & 13.33 \\
1997 & 253 & 17.00 & 5.14 & 5.93 \\
1998 & 272 & 5.51 & 3.31 & 24.63 \\
1999 & 293 & 22.87 & 19.80 & 6.83 \\
2002 & 323 & 3.41 & 4.69 & 38.40 \\
2003 & 320 & 4.38 & 5.94 & 46.25
\end{tabular}

$\mathrm{n}$ : number of analyzed samples.

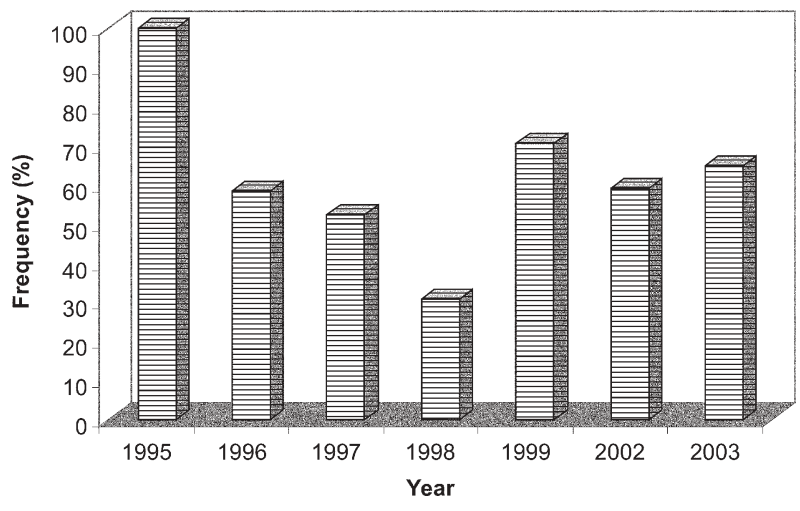

Fig. 1: frequency of Campylobacter $\mathrm{spp}$. in the infant rhesus monkeys (0 to 12 months) from Fiocruz Primate Center along the studied years.

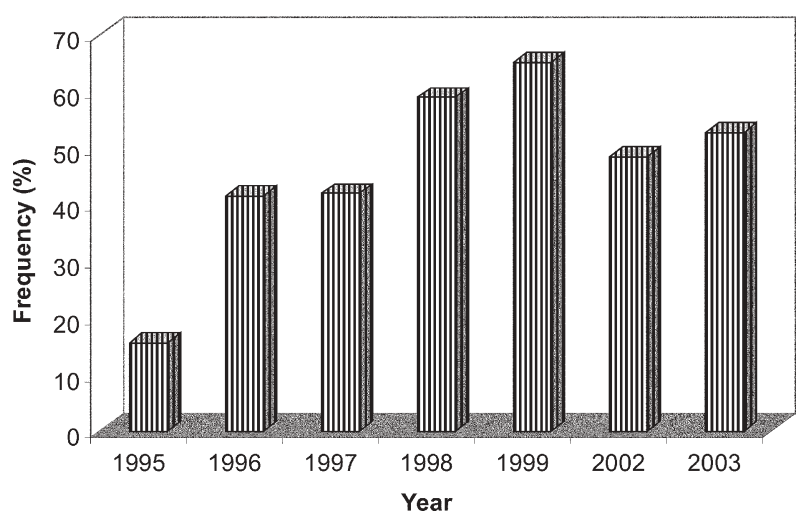

Fig. 2: frequency of Campylobacter spp. in the juvenile rhesus monkeys (13 to 48 months) from Fiocruz Primate Center along the studied years.

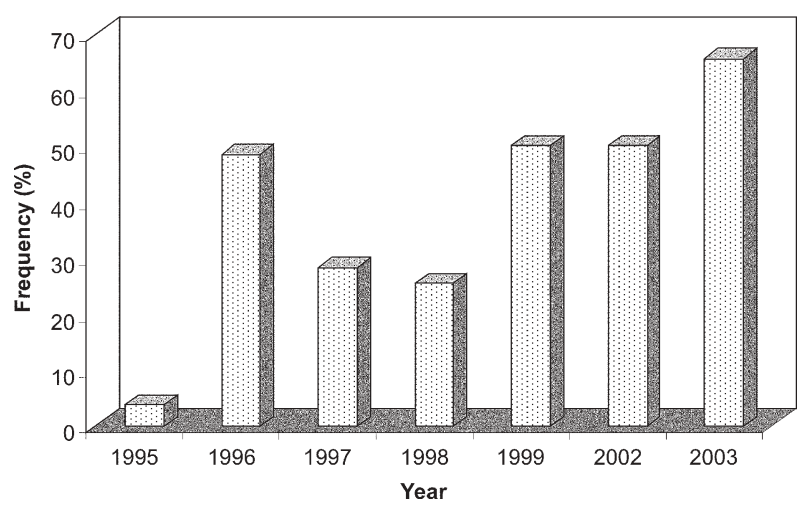

Fig. 3: frequency of Campylobacter spp. in the subadult rhesus monkeys (49 to 72 months) from Fiocruz Primate Center along the studied years.

\section{DISCUSSION}

Campylobacteriosis manifests seasonally (Mann et al. 2000) and has been identified as the principal cause of diarrheas and enterocolites in nonhuman primates (Russel et al. 1988). Cases of miscarriages have also to be taken into consideration since it has been reported that Campylobacter can induce fetal death (Baze \& Bernacky 2002). The animals here analyzed presented with sporadic diarrhea mainly during the hot months of 


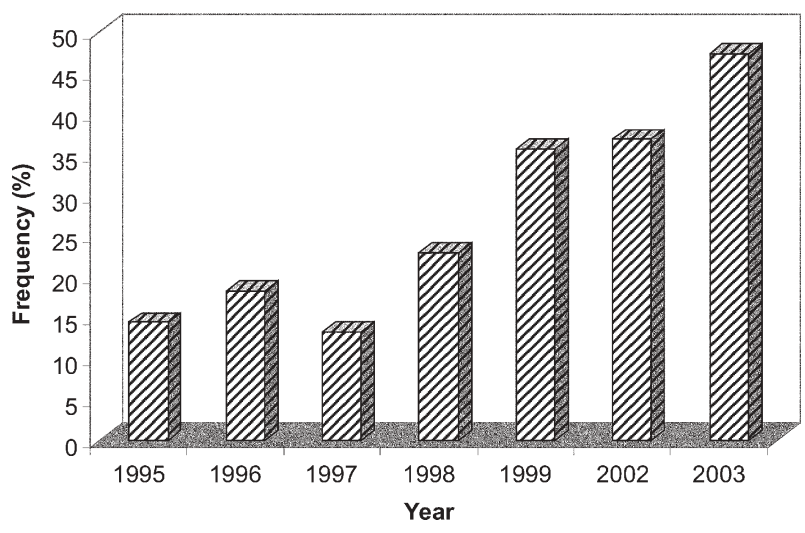

Fig. 4: frequency of Campylobacter spp. in the adult rhesus monkeys (older than 73 months) from Fiocruz Primate Center along the studied years.

TABLE III

Positivity difference (\%) of Campylobacter spp. between sexes occuring in the rhesus macaques from Fiocruz Primate Center

\begin{tabular}{llll}
\hline & \multicolumn{2}{c}{ Male } & \\
\cline { 2 - 2 } Year & \multicolumn{2}{c}{ Positivity (\%) } & $P^{a}$ \\
\hline 1995 & 14.2 & 17.7 & 0.7719 \\
1996 & 27.1 & 15.7 & 0.0380 \\
1997 & 27.3 & 23.1 & 0.0681 \\
1998 & 28.8 & 23.1 & 0.0044 \\
1999 & 53.7 & 51.6 & 0.0378 \\
2002 & 60.2 & 41.7 & 0.0041 \\
2003 & 53.0 & 55.7 & 0.0327 \\
\hline
\end{tabular}

a: P-bold: significant at 0.05 level.

the year, a fact that may be related to a higher incidence of Campylobacter. In this study, the authors did neither verify seasonalness because the collection of fecal samples was performed during another period of the year, nor was it possible to associate Campylobacter with miscarriages since abortion material has not been analyzed.

In the course of the years under study, the colony of rhesus monkey underwent different changes in the handling techniques, facilities, diet and sanitizing, with the intend of searching procedures that could influence the positivity rates for Campylobacter.

Among these modifications, in 2001 we passed to use autoclaved wood shavings inside the shelters of the cages, so avoiding the need to wash the cages daily. This way, humidity and the presence of caretakers inside the cages were reduced, contributing to less environmental contamination. This measure also contributed to minimize captivity-related stress and provided more comfort to the animals. According to Fox (1982), animals held in captivity generally suffer from environmental stress due to super-population, changes in the diet, illumination, temperature, ventilation, humidity, and frequent presence of humans. One of these factors or a combination of them induces the appearance of clinical signs of campylobacteriosis in assymptomatic animals.

In 2002 animal facilities were amplified and the colony of cynomolgus monkeys (Macaca fascicularis), which were housed in the same macro-environment with the rhesus monkeys, was transferred. Hence, a sanitary barrier was established and there is no more direct contact between the two species of primates. Fox (1982) found that animals kept under poor sanitary conditions and not adequately handled showed more susceptible to cross contamination. In the years 2002 and 2003, no decline in the bacterial charge of the colony was detected, demonstrating an unable method to control this zoonosis.

In countries with poor hygienic conditions, exposure to campylobacteriosis occurs mainly through water and food contaminated with human and/or animal excrements (Evans et al. 2003). Accordingly, in 2002 the Fiocruz Primate Center started to immerse fruits and vegetables in sodium hypochlorite solution (2\%) for $15 \mathrm{~min}$ before given to the animals, which resulted in elimination of parasites (intestinal worms) as was verified by weekly laboratory examinations carried out in the Department of Animal Quality Control from Cecal. On the other hand, this procedure was not effective to reduce or eliminate bacterial contamination in view of the Campylobacter infection persistence.

Frequency of positivity data throughout the years show a tendency of increasing, evident in the analyzed subadult and adult rhesus monkeys. This tendency is still perceivable in the juvenile group and the positivity is higher in 1999 than the other years. In the infant group we detected $100 \%$ of positivity, thus such tendency is not observed.

Russel et al. (1988) and Paul-Murphy (1993) stated that infant monkeys are extremely susceptibles to Campylobacter, showing accordance with this manuscript (Figs 1 to 4). With regards to the difference of positivity between sexes, we observe a high significance, except for the years 1995 and 1997. In general males were more infected than females.

In face of the obtained results it is obvious that the adopted methods for handling the animals are still not efficient for eliminating this bacteria under study from the rhesus colony. It thus becomes clear that the professionals that work directly with captive rhesus monkeys must be aware about the risks of Campylobacter infection and possible interference on the experimental procedures.

A better comprehension of the pathogenicity of the infection caused by Campylobacter and its natural history in this species of primates will be necessary for developing adequate control and prevention methods.

\section{REFERENCES}

Acha PN, Szyfres B 1989. Zoonosis y Enfermidades Transmissibles Comunes al Hombre y a los Animales, 2nd ed., Organización Panamericana de la Salud, Washington, 989 pp.

Andrade MCR, Ribeiro CTR, Silva VF, Molinaro EM, Gonçalves MAB, Marques MAP, Cabello PH, Leite JPG 2004. Biologic data of Macaca mulatta, Macaca fascicularis, and Saimiri sciureus used for research at the Fiocruz Primate Center. 
Mem Inst Oswaldo Cruz 99: 581-589.

Baze WB, Bernacky BJ 2002. Campylobacter-induced fetal death in a rhesus monkey. Vet Pathol 39: 605-607.

Evans MR, Ribeiro CD, Salmon RL 2003. Harzards of healthy living: bottled water and salad vegetables as risk factors for Campylobacter infection. Emerg Infect Dis 9: 1219-1225.

Fox JG 1982. Campylobacteriosis - A 'new' disease in laboratory animals. Lab Anim Sci 32: 625-637.

Lauria-Filgueiras AL 2000. Circulação de Espécies Termofilicas de Campylobacter em Primatas não Humanos Mantidos em Cativeiro, Rio de Janeiro, $\mathrm{PhD}$ Thesis, Instituto Oswaldo Cruz, Rio de Janeiro.

Lauria-Filgueiras AL, Hofer E 1989. Ocorrência de Campylobacter termofílico em diferentes pontos de uma estação de tratamento de esgotos na cidade do Rio de Janeiro, RJ. Rev Microbiol 20: 303-308.

Lauria-Filgueiras AL, Hofer E 1998. Diversity of Campylobacter isolates from three activated sludge systems. Mem Inst Oswaldo Cruz 93: 295-298.

Magalhães M, Andrade MA, Silva GP 1982. Simple and inexpensive method for culturing Campylobacter fetus subsp. jejuni. Rev Microbiol 3: 124-125.

Mann DR, Akibami MA, Gould KG, Ansari AA 2000. Seasonal variations in cytokine expression and cell-mediated immunity in male rhesus monkeys. Cel Immunol 200: 105-115.

Moore JE, Corcoran D, Dooley JS, Fanning S, Lucey B, Matsuda M, McDowell DA, Megraud F, Millar BC, O’Mahony R, O'Riordan L, O'Rourke M, Rao JR, Rooney PJ, Sails A, White P 2005. Campylobacter. Vet Res 36: 351-382.

NCCLS 2004. Performance Standards for Antimicrobial Disk Susceptibility Test, Approved Standard, 8th ed., 23 (1).

Paul-Murphy J 1993. Bacterial enterocolitis in nonhuman primates. In E Murray, Zoo and Wild Animal Medicine: Current Therapy 3, 2nd ed., M Fowler Publishing, Saunders, Philadelphia, p. 344-351.
Pennie RA, Zunino JN, Rose CE, Guerrant RL 1984. Economical, simple method for production of the gaseous environment required for cultivation of Campylobacter jejuni. $J$ Clin Microbiol 20: 320-322.

Pinheiro MS, Barrucand L, Ricciadi JD, Tibana A 1991. Evaluation of cefoxitin medium and the microaerophilic environment produced by a combination of iron, copper and sodium bicarbonate for culture of Campylobacter jejuni and Campylobacter coli. Rev Microbiol 22: 298-302.

Russel RG 1992. Campylobacter jejuni colitis and immunity in primates; epidemiology of natural infection. Am Soc Microbiol 15: 148-157.

Russel RG, Krugner L, Tsai C-C, Ekstrom R 1988. Prevalence of Campylobacter in infant, juvenile and adult laboratory primates. Lab Anim Sci 38: 711-714.

Russel RG, O’Donnoghue M, Blake-Jr DC, Zulty J, DeTolla LJ 1993. Early colonic damage and invasion of Campylobacter jejuni in experimentally challenged infant Macaca mulatta. JID 168: 210-215.

Russel RG, Rosenkranz SL, Lee LA, Howard H, DiGiacomo RF, Bronsdon MA, Blakley GA, Tsai CC, Morton WR 1987. Epidemiology and etiology of diarrhea in colony-born Macaca nemestrina. Lab Anim Sci 37: 309-316.

Sestak K, Merrit CK, Borda J, Saylor E, Schwamberger SR, Cogswell F, Didier ES, Didier PJ Plauche G, Bohm RP, Aye PP, Alexa P, Ward RL, Lackner AA 2003. Infectious agent and immune response characteristics of chronic enterocolitis in captive rhesus macaques. Infect Immun 71: 4079-4086.

Stutman HR 1994. Salmonella, Shigella, and Campylobacter: common bacterial causes of infectious diarrhea. Pediatr Ann 23: $538-543$.

Walker RI, Caldwell MB, Lee EC, Guerry P, Trust TJ, RuizPalacios GM 1986. Pathophysiology of Campylobacter enteritis. Microbiol Rev 50: 81-94.

Wassenaar TM 1997. Toxin production by Campylobacter spp. Clin Microbiol Rev 10: 466-476. 